Giorgio V. Scagliotti, University of Turin, S. Luigi Hospital, Turin, Italy; Ihor Vynnychenko, Sumy State University, Sumy; Oleksandr Sydorenko, Zaporizhzhya State Medical University, Zaporizhzhya, Ukraine; Keunchil Park, Sungkyunkwan University School of Medicine, Seoul, Korea; Yukito Ichinose, National Kyushu Cancer Center, Fukuoka; Kaoru Kubota, Nippon Medical School, Tokyo, Japan; Fiona Blackhall, The Christie National Health Services Foundation Trust, Manchester, United Kingdom; Robert Pirker, Medical University Vienna, Vienna, Austria; Rinat Galiulin, Omsk Regional Oncology Center, Omsk, Russia; Tudor-Eliade Ciuleanu, Oncology Institute Ion Chiricuta, Clui-Napoca; Mircea Dediu, Institute of Oncology, Bucharest, Romania Zsolt Papai-Szekely, St George Hospital, Szekesfehervar, Hungary; Natividad Martinez Banaclocha, Hospital General Universitario, Elche, Spain; Sheryl McCoy, Bin Yao, Yong-jiang Hei, Francesco Galimi, Amgen, Thousand Oaks, CA; and David R. Spigel, Sarah Cannon Research Institute and Tennessee Oncology, Nashville, TN.

Submitted December 30, 2011; accepted April 16, 2012; published online ahead of print at www.jco.org on July 2, 2012.

Supported by Amgen

Presented in part at 47th Annual Meeting of the American Society of Clinical Oncology, June 3-7, 2011, Chicago, IL.

Authors' disclosures of potential conflicts of interest and author contributions are found at the end of this article.

Clinical Trials repository link available on JCO.org.

Corresponding author: Giorgio V. Scagliotti $\mathrm{MD}$, Department of Clinical and Biological Sciences, University of Turin, San Luigi Hospital, Regione Gonzole 10, Orbassano, Torino, Italy 10043; e-mail: scagliotti@ innet.it.

๑) 2012 by American Society of Clinical Oncology

0732-183X/12/3023-2829/\$20.00

DOI: 10.1200/JCO.2011.41.4987

\title{
International, Randomized, Placebo-Controlled, Double-Blind Phase III Study of Motesanib Plus Carboplatin/Paclitaxel in Patients With Advanced Nonsquamous Non-Small-Cell Lung Cancer: MONET1
}

Giorgio V. Scagliotti, Ihor Vynnychenko, Keunchil Park, Yukito Ichinose, Kaoru Kubota, Fiona Blackhall, Robert Pirker, Rinat Galiulin, Tudor-Eliade Ciuleanu, Oleksandr Sydorenko, Mircea Dediu, Zsolt Papai-Szekely, Natividad Martinez Banaclocha, Sheryl McCoy, Bin Yao, Yong-jiang Hei, Francesco Galimi, and David R. Spigel

See accompanying editorial on page 2805

$\begin{array}{llllllll}\text { A } & \text { B } & \text { S } & \text { T } & \text { R } & \text { A } & \text { C } & \text { T }\end{array}$

\section{Purpose}

We evaluated whether motesanib (a selective oral inhibitor of vascular endothelial growth factor receptors 1, 2, and 3; platelet-derived growth factor receptor; and Kit) combined with carboplatin/ paclitaxel improved overall survival (OS) versus chemotherapy alone in patients with nonsquamous non-small-cell lung cancer (NSCLC) and in the subset of patients with adenocarcinoma.

\section{Patients and Methods}

Patients with stage IIIB/IV or recurrent nonsquamous NSCLC (no prior systemic therapy for advanced disease) were randomly assigned 1:1 to carboplatin (area under the curve, $6 \mathrm{mg} / \mathrm{ml} \cdot \mathrm{min}$ ) and paclitaxel $\left(200 \mathrm{mg} / \mathrm{m}^{2}\right)$ intravenously for up to six 3-week cycles plus either motesanib $125 \mathrm{mg}(\mathrm{arm} \mathrm{A})$ or placebo (arm B) once daily orally. OS was the primary end point. Secondary end points included progression-free survival (PFS), objective response rate (ORR), adverse events (AEs), and association between placental growth factor (PLGF) change and OS.

\section{Results}

A total of 1,090 patients with nonsquamous NSCLC were randomly assigned (arms $A / B, n=541$ of 549); of those, 890 had adenocarcinoma ( $n=448$ of 442). Median OS in arms A and B was 13.0 and 11.0 months, respectively (hazard ratio $[\mathrm{HR}], 0.90 ; 95 \% \mathrm{Cl}, 0.78$ to $1.04 ; P=.14$ ); median OS for the adenocarcinoma subset was 13.5 and 11.0 months, respectively $(\mathrm{HR}, 0.88 ; 95 \% \mathrm{Cl}, 0.75$ to 1.03; $P=.11$ ). In descriptive analyses (arms $A \vee B$ ), median PFS was 5.6 months versus 5.4 months $(P=<.001)$; ORR was $40 \%$ versus $26 \%(P<.001)$. There was no association between PLGF change and OS in arm A. The incidence of grade $\geq 3$ AEs (arms A and B, 73\% and 59\%, respectively) and grade 5 AEs (14\% and 9\%, respectively) was higher with motesanib treatment.

\section{Conclusion}

Motesanib plus carboplatin/paclitaxel did not significantly improve OS over carboplatin/paclitaxel alone in patients with advanced nonsquamous NSCLC or in the adenocarcinoma subset.

\section{J Clin Oncol 30:2829-2836. (C) 2012 by American Society of Clinical Oncology}

\section{INTRODUCTION}

Two pivotal phase III trials have laid the foundation for using targeted antiangiogenic agents in the treatment of metastatic nonsquamous non-small-cell lung cancer (NSCLC). In the E4599 study, treatment with bevacizumab, an anti-vascular endothelial growth factor (VEGF) monoclonal antibody, combined with carboplatin/paclitaxel significantly improved objective response rate (ORR), progressionfree survival (PFS), and overall survival (OS) compared with carboplatin/paclitaxel alone. ${ }^{1}$ In the
AVAiL (AVAstin in Lung) study, bevacizumab plus cisplatin/gemcitabine improved PFS and ORR, compared with placebo, but not OS.,3

Efforts to identify drugs that inhibit key signaling pathways involved in the pathogenesis of cancer have led to the development of multitargeted agents. Small-molecule tyrosine kinase inhibitors that block several kinases simultaneously may offer advantages over single-target agents. ${ }^{4}$ Furthermore, there is interest in identifying patients most likely to respond to targeted therapies based on specific biomarkers ${ }^{5}$ and/or tumor histology. ${ }^{6}$ 
Motesanib is a selective oral inhibitor of VEGF receptors (VEGFR) 1, 2, and 3; platelet-derived growth factor receptor; and $\mathrm{Kit}^{7}$ that has demonstrated antitumor activity when administered as monotherapy ${ }^{8-10}$ or combined with chemotherapy. ${ }^{11}$ In a phase II randomized, open-label study in advanced nonsquamous NSCLC, ORR, PFS, and OS were estimated to be comparable among patients who received carboplatin/paclitaxel and either motesanib $125 \mathrm{mg}$ once daily $(\mathrm{n}=61)$ or bevacizumab $15 \mathrm{mg} / \mathrm{kg}$ once every 3 weeks $(\mathrm{n}=63) .{ }^{11} \mathrm{~A}$ biomarker analysis of that study showed significant associations between increase in placental growth factor (PLGF) during the first 3 weeks of treatment and efficacy outcomes in the motesanib 125-mg once daily arm. ${ }^{12}$ PLGF is a VEGF homolog that can promote angiogenesis by activating VEGFR-1. ${ }^{13}$

The primary objective of the MONET1 (Motesanib NSCLC Efficacy and Tolerability) study was to determine whether motesanib combined with carboplatin/paclitaxel improved OS, compared with placebo plus carboplatin/paclitaxel, in patients with advanced nonsquamous NSCLC and in the subset of patients with adenocarcinoma histology. We also assessed whether increases in PLGF during motesanib treatment were associated with OS.

\section{PATIENTS AND METHODS}

\section{Eligibility}

Initially, the study enrolled patients with NSCLC of all histologies. After a planned review of data from 600 patients (including 223 with squamous histology) in November 2008, the independent data monitoring committee recommended that enrollment of all patients be halted and treatment of those with squamous histology be discontinued because of higher early mortality and a higher incidence of gross hemoptysis compared with placebo. Patients with nonsquamous histology continued to receive treatment. The study protocol was amended in April 2009 to only allow enrollment of patients with nonsquamous histology; enrollment resumed in June 2009. This article reports results from the amended study.

Eligible patients ( $\geq 18$ years of age) had histologically confirmed unresectable stage IIIB with pericardial/pleural effusion or stage IV/recurrent nonsquamous NSCLC; measurable or nonmeasurable disease per Response Evaluation Criteria in Solid Tumors (RECIST 1.0) ${ }^{14}$; Eastern Cooperative Oncology Group performance status $\leq 1$; life expectancy $\geq 3$ months; and adequate renal, cardiac, hepatic, and hematologic function. Key exclusion criteria were history of pulmonary hemorrhage or gross hemoptysis within 6 months of randomization; prior chemotherapy, including adjuvant chemotherapy within 52 weeks of randomization; symptomatic or untreated CNS metastases; adenosquamous histology or unclear histologic type ( $>10 \%$ squamous cells); prior targeted therapy; uncontrolled hypertension; arterial or venous thrombosis within 12 months, or bleeding diathesis or bleeding within 14 days of randomization. Study procedures were approved by an independent ethics committee/institutional review board at each study site. All patients provided written informed consent.

\section{Study Design and Treatments}

The study was conducted at 198 centers in 32 countries. Patients received paclitaxel $\left(200 \mathrm{mg} / \mathrm{m}^{2}\right)$ and carboplatin (area under the curve, $6 \mathrm{mg} / \mathrm{ml} \cdot \mathrm{min}$ ) on day 1 of each 3-week cycle for up to six cycles and were randomly assigned 1:1 using a computerized interactive voice response system to also receive oral motesanib $125 \mathrm{mg}$ once daily (arm A) or placebo (arm B). Randomization was stratified by disease stage (IIIB $v$ IV/recurrent), weight loss in the previous 6 months before randomization $(<5 \%$ $v \geq 5 \%$ ), sex (male $v$ female), and prior adjuvant chemotherapy (yes $v$ no). Treatment continued until disease progression, unacceptable toxicity, or withdrawal of consent.
In case of treatment-related grade 3 or 4 toxicity, motesanib/placebo was withheld until the toxicity resolved to grade $\leq 1$ or baseline. Treatment could then be resumed with a $25-\mathrm{mg}$ dose reduction but was permanently discontinued if more than two dose reductions were required or if grade 3 or 4 toxicity recurred after a dose delay and/or reduction or persisted for more than 3 weeks.

The primary end point was OS. Secondary end points included PFS (from randomization to disease progression per RECIST), ORR per RECIST 1.0 , and incidence of adverse events (AEs). Before unblinding, the statistical analysis plan was amended to also assess association between motesanib treatment-induced PLGF change and OS as a secondary end point.

\section{Assessments}

Computed tomography/magnetic resonance imaging was performed every $6 \pm 1$ weeks for assessment of tumor response by investigators. Objective responses were confirmed $\geq 4$ weeks after the initial response assessment. If symptoms suggestive of disease progression occurred, patients were evaluated for tumor response.

All AEs (from the start of treatment to 30 days after the last dose) were recorded and graded according to the National Cancer Institute Common Terminology Criteria for Adverse Events, version 3.0.

\section{Biomarker Analysis}

Serum samples were obtained before treatment on day 1 of cycles 1, 2, and 3 and every 6 weeks thereafter. Serum PLGF was quantified using a two-step chemiluminescent microparticle immunoassay (ARCHITECT; Abbott Laboratories, Abbott Park, IL). Briefly, serum sample and anti-PLGF antibody paramagnetic microparticles were incubated together; following a wash step, anti-PLGF acridinium-labeled antibody was added. After another incubation and wash, pretrigger and trigger solutions were added, and chemiluminescent signal was measured. The lower limit of quantitation was 3.4 $\mathrm{pg} / \mathrm{mL}$; the linear response range was 4 to $1,500 \mathrm{pg} / \mathrm{mL}$.

\section{Statistical Analysis}

The study was designed to accrue approximately 1,060 patients with nonsquamous histology to have $80 \%$ power to detect a hazard ratio (HR) of 0.80 (12.5 months $v 10$ months) for OS with two-sided $\alpha=.03$ in the patients with nonsquamous histology. The study had $80 \%$ power to detect an HR of 0.77 (13 months $v 10$ months) for OS with two-sided $\alpha=.02$ in the adenocarcinoma subset. An $\alpha$ split testing strategy was used to control the overall type I error rate of the study. The primary analysis was planned at 742 and 593 deaths among patients with nonsquamous histology and the adenocarcinoma subset, respectively, whichever occurred later. An interim analysis was planned at 370 events among nonsquamous patients; early stopping guidelines are described in the study protocol (Data Supplement).

OS and PFS were compared between arms A and B using stratified log-rank tests based on the stratification factors at randomization. HRs for the effect of motesanib on OS and PFS between arms A and B were estimated using a stratified Cox proportional hazards model. ${ }^{15}$ Difference in ORR between arms $A$ and $B$ was calculated with a stratified Cochran-Mantel-Haenszel test ${ }^{15}$ using the randomization stratification factors. The association between motesanib treatment-induced PLGF change and OS was evaluated using a Cox model with the log-transformed fold-change in PLGF from baseline at week 4 as a continuous variable. If OS and PLGF were significantly associated, foldchange in PLGF was to be assessed based on a prespecified cutoff $(\geq 2.0$-fold $v<2$.0-fold change). A hierarchical testing scheme for the secondary efficacy end points (PFS, PLGF, and ORR) was specified if the primary end point (OS) was met.

Efficacy analyses for OS and PFS included all randomly assigned patients with nonsquamous histology following the intent-to-treat principle. Safety analyses included all randomly assigned patients who received one or more doses of motesanib/placebo. Biomarker analyses included all patients randomly assigned who had PLGF values at weeks 1 (baseline) and 4 and had received motesanib/placebo the day before the week 4 PLGF sample collection. 


\section{RESULTS}

\section{Patients}

Between July 5, 2007, and March 18, 2010, 1,090 patients with nonsquamous NSCLC were randomly assigned to motesanib $(\mathrm{n}=541$; $\operatorname{arm} A)$ or placebo $(n=549$; $\operatorname{arm} B)$. Before the protocol amendment, the study also enrolled 360 patients with squamous histology. Data from this cohort will be reported in a separate publication. Eighteen patients with nonsquamous NSCLC did not receive motesanib $(\mathrm{n}=10)$ or placebo $(\mathrm{n}=8$; Fig 1). Most patients had adenocarcinoma histology (arm A, 83\%; arm B, $81 \%$ ), weight loss less than $5 \%$ in the previous 6 months, and stage IV/recurrent disease (Table 1). Clinical characteristics were generally balanced across treatment arms.

\section{Treatment}

Median daily doses of motesanib or placebo were $125 \mathrm{mg}$ in both treatment arms. Patients received motesanib for a median of 4.1 months (range, 0.03 to 35.9 months) and placebo for 4.1 months (range, 0.03 to 31.5 months). Carboplatin was administered for a median of 4.5 cycles (range, one to six cycles) in arm A and 5.0 cycles (range, one to six cycles) in arm B; paclitaxel was administered for a median of 4.0 cycles (range, one to six cycles) in arm A and 5.0 cycles (range, one to six cycles) in arm B. At the time of this analysis, 519 patients (96\%) in arm A and 534 patients (97\%) in arm B had discon- tinued motesanib/placebo; more patients in arm A than arm B had discontinued for reasons other than disease progression (Fig 1). Median follow-up times were 11 months (range, 0.2 to 41 months) in arm A and 10 months (range, 0.2 to 38 months) in arm B.

\section{OS}

Treatment with motesanib did not significantly improve OS. At the time of this analysis, $66 \%$ of patients in arm $\mathrm{A}$ and $72 \%$ in $\operatorname{arm} \mathrm{B}$ had died. Among all patients with nonsquamous histology, median OS times were 13.0 months (95\% CI, 11.2 to 14.0 months) in arm A versus 11.0 months (95\% CI, 10.1 to 12.4 months) in arm B (HR, 0.90; $95 \% \mathrm{CI}, 0.78$ to $1.04 ; P=.14$; Fig $2 \mathrm{~A})$. In the adenocarcinoma subset, median OS time was 13.5 months (95\% CI, 11.3 to 14.7 months) in arm A versus 11.0 months (95\% CI, 9.9 to 12.4 months) in $\operatorname{arm~B~(HR,~}$ 0.88 ; $95 \%$ CI, 0.75 to 1.03 ; $P=.11$; Fig $2 \mathrm{~B}$ ). Prespecified subgroup analyses suggested longer survival among patients receiving motesanib who were nonwhite (HR, $0.76 ; 95 \% \mathrm{CI}, 0.59$ to $0.97 ; \mathrm{n}=375$ ) or who were enrolled outside the United States/Canada/Australia/European Union (HR, 0.77; 95\% CI, 0.61 to 0.98 ; n = 414; Fig 3).

\section{PFS}

Among all patients with nonsquamous histology, median PFS times were 5.6 months in arm A versus 5.4 months in $\operatorname{arm~B~(HR,~} 0.79 ; 95 \% \mathrm{CI}$, 0.68 to $0.90 ; P=<.001$; Fig $4 \mathrm{~A})$. PFS times in the adenocarcinoma

\begin{tabular}{|c|c|c|c|}
\hline & \multicolumn{3}{|c|}{$\begin{array}{l}\text { Nonsquamous and squamous patients screened } \\
\qquad(N=1,874)\end{array}$} \\
\hline & \multicolumn{3}{|c|}{$\begin{array}{l}\text { Nonsquamous patients randomly assigned } \\
\qquad(\mathrm{n}=1,090)\end{array}$} \\
\hline $\begin{array}{l}\text { Arm A: Motesanib } 125 \mathrm{mg} \text { QD }+\mathrm{C} / \mathrm{P} \\
\text { Received motesanib } \\
\text { Did not receive motesanib }\end{array}$ & $\begin{array}{r}(n=541) \\
(n=531) \\
(n=10)\end{array}$ & $\begin{array}{l}\text { Arm B: Placebo + C/P } \\
\text { Received placebo } \\
\text { Did not receive placebo }\end{array}$ & $\begin{array}{r}(n=549) \\
(n=541) \\
(n=8)\end{array}$ \\
\hline $\begin{array}{l}\text { Ongoing } \\
\text { Discontinued motesanib } \\
\text { Disease progression } \\
\text { Adverse event } \\
\text { Consent withdrawn } \\
\text { Patient request } \\
\text { Administrative decision } \\
\text { Death } \\
\text { Lost to follow-up } \\
\text { Noncompliance } \\
\text { Protocol deviation } \\
\text { Other }\end{array}$ & $\begin{array}{r}(\mathrm{n}=12) \\
(\mathrm{n}=519) \\
(\mathrm{n}=246) \\
(\mathrm{n}=150) \\
(\mathrm{n}=27) \\
(\mathrm{n}=28) \\
(\mathrm{n}=27) \\
(\mathrm{n}=27) \\
(\mathrm{n}=5) \\
(\mathrm{n}=3) \\
(\mathrm{n}=2) \\
(\mathrm{n}=4)\end{array}$ & $\begin{array}{l}\text { Ongoing } \\
\text { Discontinued placebo } \\
\text { Disease progression } \\
\text { Adverse event } \\
\text { Consent withdrawn } \\
\text { Patient request } \\
\text { Administrative decision } \\
\text { Death } \\
\text { Lost to follow-up } \\
\text { Noncompliance } \\
\text { Protocol deviation } \\
\text { Ineligibility determined } \\
\text { Other } \\
\text { Missing }\end{array}$ & $\begin{array}{r}(n=7) \\
(n=534) \\
(n=350) \\
(n=70) \\
(n=32) \\
(n=18) \\
(n=19) \\
(n=19) \\
(n=4) \\
(n=6) \\
(n=2) \\
(n=8) \\
(n=5) \\
(n=1)\end{array}$ \\
\hline $\begin{array}{l}\text { Analyzed for efficacy } \\
\text { All randomly assigned patients wit } \\
\text { Adenocarcinoma subset } \\
\text { Excluded from efficacy analysis } \\
\text { Analyzed for safety }\end{array}$ & $\begin{array}{l}\text { us histology }(n=541) \\
(n=448) \\
(n=0) \\
(n=533)^{*}\end{array}$ & $\begin{array}{l}\text { Analyzed for efficacy } \\
\text { All randomly assigned patients with nonsquamous histology } \\
\text { Adenocarcinoma subset } \\
\text { Excluded from efficacy analysis } \\
\text { Analyzed for safety }\end{array}$ & $\begin{array}{r}(n=549) \\
(n=442) \\
(n=0) \\
(n=539)^{*}\end{array}$ \\
\hline
\end{tabular}

Fig 1. Disposition of patients. $\left(^{*}\right)$ Two patients assigned to placebo treatment received at least one dose of motesanib. C/P, carboplatin/paclitaxel; $Q D$, once daily. 


\begin{tabular}{|c|c|c|c|c|}
\hline \multirow[b]{2}{*}{ Characteristic } & \multicolumn{2}{|c|}{$\begin{array}{c}\text { Arm A, } \\
\text { Motesanib + } \\
\text { C/P }(n=541) \\
\end{array}$} & \multicolumn{2}{|c|}{$\begin{array}{c}\text { Arm B, } \\
\text { Placebo + } \\
\text { C/P }(n=549 \\
\end{array}$} \\
\hline & No. & $\%$ & No. & $\%$ \\
\hline \multicolumn{5}{|l|}{ Age, years } \\
\hline Median & \multicolumn{2}{|c|}{60} & \multicolumn{2}{|c|}{60} \\
\hline Range & \multicolumn{2}{|c|}{$23-87$} & \multicolumn{2}{|c|}{$21-84$} \\
\hline Men‡ & 334 & 62 & 336 & 61 \\
\hline \multicolumn{5}{|l|}{ ECOG performance status } \\
\hline 0 & 188 & 35 & 207 & 38 \\
\hline$\geq 1$ & 353 & 65 & 342 & 62 \\
\hline Past or present smoker & 387 & 72 & 397 & 72 \\
\hline \multicolumn{5}{|l|}{ Race } \\
\hline White & 362 & 67 & 353 & 64 \\
\hline Asian§ & 139 & 26 & 148 & 27 \\
\hline Hispanic & 28 & 5 & 38 & 7 \\
\hline Black & 9 & 2 & 7 & 1 \\
\hline Other & 3 & $<1$ & 3 & $<1$ \\
\hline \multicolumn{5}{|l|}{ Histology } \\
\hline Adenocarcinoma & 448 & 83 & 442 & 81 \\
\hline Bronchoalveolar carcinoma & 14 & 3 & 15 & 3 \\
\hline Large-cell carcinoma & 26 & 5 & 35 & 6 \\
\hline Undifferentiated & 21 & 4 & 21 & 4 \\
\hline Other & 32 & 6 & 36 & 7 \\
\hline \multicolumn{5}{|l|}{ Disease stage at study entry $\ddagger$} \\
\hline IIIB with pericardial/pleural effusion & 73 & 13 & 79 & 14 \\
\hline IV/recurrent & 468 & 87 & 470 & 86 \\
\hline $\begin{array}{l}\text { Weight loss }<5 \% \text { in previous } 6 \\
\text { monthst }\end{array}$ & 397 & 73 & 407 & 74 \\
\hline Prior adjuvant chemotherapy $\ddagger$ & 11 & 2 & 12 & 2 \\
\hline \multicolumn{5}{|c|}{$\begin{array}{l}\text { Abbreviations: C/P, carboplatin/paclitaxel; ECOG, Eastern Cooperative Oncol } \\
\text { ogy Group. } \\
{ }_{\text {*All randomly assigned patients with nonsquamous histology. }} \\
\text { †Randomization stratification factors. } \\
\text { §lncludes Japanese patients. }\end{array}$} \\
\hline
\end{tabular}

subset were similar: 5.6 months in arm A versus 5.4 months in arm B (HR, 0.78; 95\% CI, 0.67 to $0.91 ; P=.0016$; Fig 4B). $P$ values for PFS and other secondary efficacy end points are exploratory because the study end point (OS) was not achieved.

\section{Tumor Response}

Most patients had measurable disease at baseline (Table 2). In exploratory analyses, ORR for all patients with nonsquamous histology (arm A, 40\% v arm B, 26\%) and for the adenocarcinoma subset ( $\operatorname{arm~A,~39\% ~} v$ arm B, 25\%) favored arm A. Likewise, in both the overall nonsquamous population ( $\operatorname{arm~A,~80\% ~v~arm~B,~74\% )~and~the~}$ adenocarcinoma subset (arm A, 81\% v arm B, 74\%), more patients receiving motesanib than placebo had a decrease in the sum of longest diameter at any time after baseline. Duration of response was 5.8 months (95\% CI, 5.3 to 6.5 months) in arm A and 5.0 months (95\% CI, 4.4 to 5.6 months) in arm B.

\section{Toxicity}

Toxicity data are reported for all randomly assigned patients with nonsquamous histology. The incidence of grade 3 AEs was similar with both treatments; however, grade 4 and grade 5 AEs as well as serious grade $\geq 3$ AEs occurred more frequently in arm A (Table 3). No specific events accounted for the imbalance in the incidence of grade 4 or 5 AEs with the exception of grade 4 neutropenia (12\% of patients in arm A $v 6 \%$ in arm B). Considering all AEs, there were a number of events that occurred at an increased incidence of $\geq 5 \%$ in arm A compared with placebo (Table 3). Particularly noteworthy were diarrhea, nausea, vomiting, and abdominal pain as well as hypertension, pneumonia, and gallbladder-related disorders (eg, cholecystitis, cholelithiasis, and gallbladder enlargement), some of which were also reported as serious grade $\geq 3$ AEs.

The incidence of AEs typically associated with VEGF pathway inhibitors was higher in arm A with respect to hypertension (Table 3 ) and grade $\geq 3$ arterial thromboembolic $(2 \% v<1 \%$ in arm B) and hemorrhagic events $(3 \% \vee 1 \%)$. Specific hemorrhagic events were gastrointestinal hemorrhage $(\mathrm{n}=1 v \mathrm{n}=0)$, pulmonary hemorrhage $(\mathrm{n}=2 v \mathrm{n}=1)$, and hemoptysis $(\mathrm{n}=3 v \mathrm{n}=1)$. Grade $\geq 3$ venous thromboembolic events occurred in $4 \%$ of patients in each treatment arm.

The number of patients with AEs leading to motesanib/placebo discontinuation was higher in arm A (31\%) than in arm B (15\%). Fourteen percent of patients in arm A and 9\% in arm B had fatal AEs while on study (ie, within 30 days of the last study treatment). Grade 5 AEs reported in four or more patients in either treatment arm were
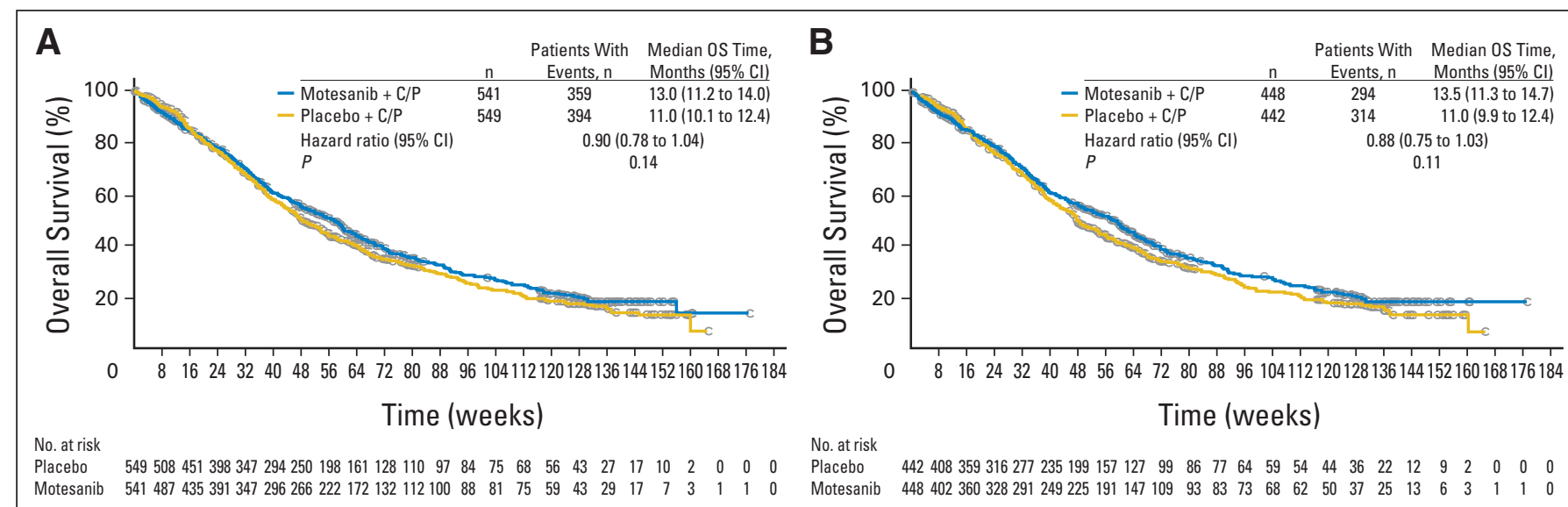

Fig 2. Overall survival (OS) time among patients who received motesanib $125 \mathrm{mg}$ once daily plus carboplatin/paclitaxel (C/P) or placebo plus $\mathrm{C} / \mathrm{P}$ in (A) all randomly assigned patients with nonsquamous histology and (B) the adenocarcinoma subset. 


\begin{tabular}{|c|c|c|c|}
\hline & $\mathrm{n}$ & Hazard ratio (motesanib/placebo) & Hazard ratio $(95 \% \mathrm{Cl}$ \\
\hline All randomly assigned & 1,090 & - & 0.901 (0.781 to 1.040$)$ \\
\hline \multicolumn{4}{|l|}{ Histology } \\
\hline Adenocarcinoma & 890 & $\rightarrow+$ & $0.880(0.751$ to 1.032$)$ \\
\hline Non-adenocarcinoma & 200 & — & $1.012(0.730$ to 1.405$)$ \\
\hline \multicolumn{4}{|l|}{ Stage of disease at enrollment } \\
\hline Stage IIIB with pericardial/pleural effusion & 152 & - & 1.034 (0.692 to 1.544$)$ \\
\hline Stage IV/recurrent & 938 & $\rightarrow$ & 0.881 (0.756 to 1.027$)$ \\
\hline \multicolumn{4}{|l|}{ Weight loss in the previous 6 months } \\
\hline$<5 \%$ & 804 & - & 0.882 (0.744 to 1.045$)$ \\
\hline$\geq 5 \%$ & 206 & $\rightarrow-$ & 0.926 (0.709 to 1.209$)$ \\
\hline \multicolumn{4}{|l|}{ Prior adjuvant chemotherapy } \\
\hline Yes & 23 & & 0.759 (0.202 to 2.846$)$ \\
\hline No & 1,067 & $\rightarrow$ & 0.905 (0.783 to 1.045$)$ \\
\hline \multicolumn{4}{|l|}{ Sex } \\
\hline Male & 670 & - & $0.950(0.795$ to 1.135$)$ \\
\hline Female & 420 & —- & $0.831(0.652$ to 1.057$)$ \\
\hline \multicolumn{4}{|l|}{ Region of enrollment } \\
\hline United States/Canada/Australia & 162 & - & $1.066(0.762$ to 1.491$)$ \\
\hline European Union & 514 & - & 0.964 (0.778 to 1.194$)$ \\
\hline Rest of the world & 414 & $\longrightarrow-$ & $0.770(0.608$ to 0.976$)$ \\
\hline \multicolumn{4}{|l|}{ Prior radiotherapy } \\
\hline Yes & 156 & - & $1.077(0.737$ to 1.576$)$ \\
\hline No & 934 & $\rightarrow$ & $0.878(0.752$ to 1.025$)$ \\
\hline \multicolumn{4}{|l|}{ Brain metastasis } \\
\hline Yes & 80 & - & 1.315 (0.758 to 2.279 ) \\
\hline No & 1,009 & $-\infty$ & $0.879(0.758$ to 1.020$)$ \\
\hline \multicolumn{4}{|l|}{ Age grouping 1} \\
\hline$<65$ & 720 & - & 0.865 (0.725 to 1.032$)$ \\
\hline$\geq 65$ & 370 & -1 & 0.977 (0.765 to 1.247$)$ \\
\hline \multicolumn{4}{|l|}{ Age grouping 2} \\
\hline$<75$ & 1,035 & $\rightarrow-$ & 0.891 (0.769 to 1.032$)$ \\
\hline$\geq 75$ & 55 & 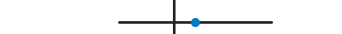 & 1.202 (0.626 to 2.310 ) \\
\hline \multicolumn{4}{|l|}{ Race } \\
\hline White & 715 & - & $0.983(0.825$ to 1.171$)$ \\
\hline All others & 315 & - & $0.757(0.590$ to 0.971$)$ \\
\hline \multicolumn{4}{|l|}{ Smoking history } \\
\hline$\geq 100$ cigarettes in a lifetime & 784 & - & 0.926 (0.785 to 1.092$)$ \\
\hline$<100$ cigarettes in a lifetime & 304 & 一. & $0.862(0.646$ to 1.151$)$ \\
\hline \multicolumn{4}{|l|}{ Baseline ECOG performance status } \\
\hline 0 & 395 & $\longrightarrow$ & $0.904(0.712$ to 1.148$)$ \\
\hline \multirow{3}{*}{$\geq 1$} & 695 & $\rightarrow f$ & $0.888(0.743$ to 1.062$)$ \\
\hline & 0. & 1 & 10 \\
\hline & & notesanib & \\
\hline
\end{tabular}

Fig 3. Overall survival time by patient subgroups for all randomly assigned patients with nonsquamous histology. European Union countries include Austria, Bulgaria, Czech Republic, France, Germany, Greece, Hungary, Ireland, Italy, Poland, Romania, Slovakia, Spain, and United Kingdom. ECOG, Eastern Cooperative Oncology Group. pneumonia ( $\mathrm{n}=7 v \mathrm{n}=0$ ), general physical health deterioration $(\mathrm{n}=6 v \mathrm{n}=1)$, respiratory failure $(\mathrm{n}=5 v \mathrm{n}=2)$, pulmonary embolism $(\mathrm{n}=3 v \mathrm{n}=6)$, and cardiorespiratory arrest $(\mathrm{n}=1 v \mathrm{n}=4)$.

\section{Assessment of PLGF As a Biomarker}

MONET1 confirmed the pharmacodynamic increase in PLGF in response to motesanib treatment that was reported previously $y^{9,12,16,17}$ (data not shown). However, among patients in the motesanib arm who had evaluable PLGF samples at baseline $(n=356,33 \%)$, there was no association between the log-transformed fold-change in PLGF from baseline to week 4 (continuous variable) and OS (unadjusted Cox model, HR, 0.98; 95\% CI, 0.79 to $1.22 ; P=.868$ ). There was no association between the prespecified $\geq 2.0$-fold change in PLGF from baseline at week 4 and OS (HR, 0.88 ; 95\% CI, 0.67 to $1.15, P=.340$ ). Similarly, there was no association between a $\geq 2.0$-fold change in PLGF and PFS or ORR.

\section{DISCUSSION}

In this large phase III study, motesanib plus carboplatin/paclitaxel did not significantly improve OS compared with placebo plus carbopla- tin/paclitaxel in the overall nonsquamous patient population or the subset of patients with adenocarcinoma. Although the study did not meet its primary end point, improvements in PFS and ORR in arm A suggest some antitumor activity of the combination in this setting. However, the study also showed that motesanib treatment was associated with increased toxicity, which may have affected efficacy. Specifically, the incidence of grade 4 and 5 AEs, serious grade $\geq 3 \mathrm{AEs}$, and AEs leading to discontinuation was higher with motesanib treatment. Gastrointestinal events, hypertension, pneumonia, cholecystitis, and other gallbladder-related disorders generally occurred more frequently in the motesanib arm, which is consistent with previous motesanib studies in advanced nonsquamous NSCLC. ${ }^{11,18}$ Cholecystitis in particular is a motesanib-specific AE that had emerged in earlier monotherapy and chemotherapy combination studies. ${ }^{8,9,11,18-20}$ Most of these AEs are likely the result of motesanib's actions on angiogenic signaling pathways (motesanib potently inhibits VEGFR1, -2, and -3; Kit; and $\mathrm{PDGFR}^{7}$ ). Toxicity in the motesanib arm appeared to have contributed to treatment discontinuation and may also have resulted in noncompliance with treatment. The study initially permitted enrollment of both nonsquamous and squamous NSCLC; however, the protocol was later amended to 


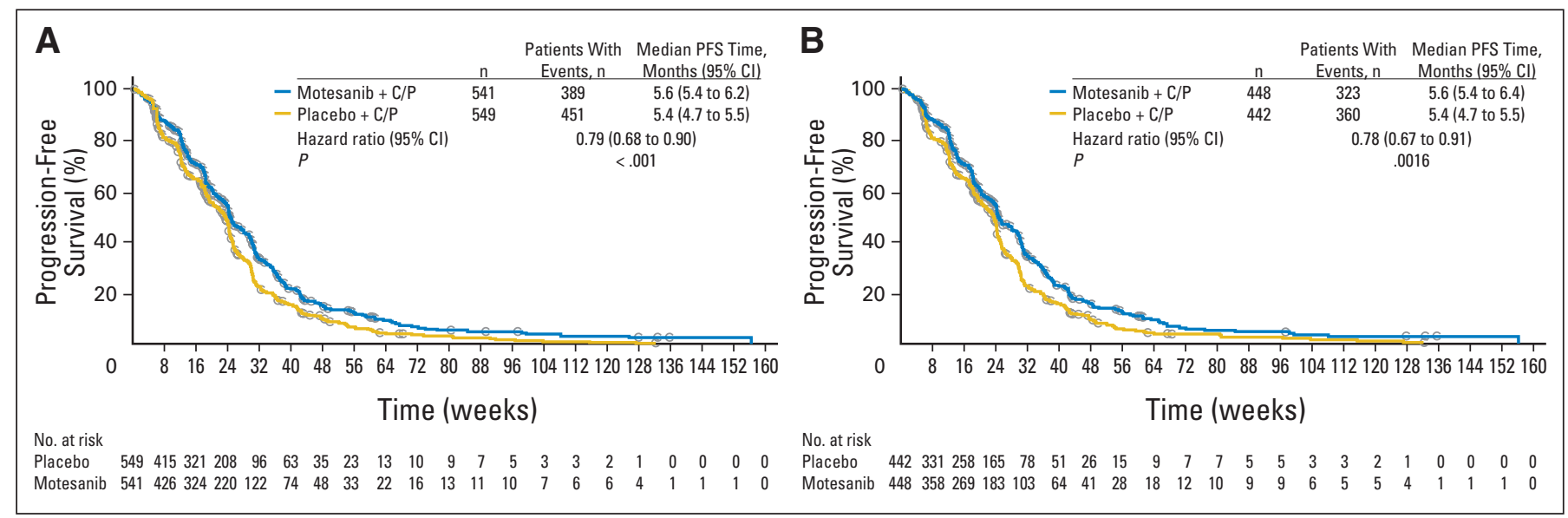

Fig 4. Progression-free survival time among patients who received motesanib $125 \mathrm{mg}$ once daily plus carboplatin/paclitaxel (C/P) or placebo plus $\mathrm{C} / \mathrm{P}$ in (A) all randomly assigned patients with nonsquamous histology and (B) the adenocarcinoma subset.

exclude patients with squamous histology because of an increased risk of death and hemoptysis. This finding was consistent with the greater risk of hemoptysis reported for patients with squamous NSCLC who received bevacizumab, ${ }^{21}$ but not with results from the Evaluation of Sorafenib, Carboplatin, and Paclitaxel Efficacy in NSCLC (ESCAPE) study, which showed no increased risk of fatal bleeding events with sorafenib treatment among patients with squamous histology. ${ }^{22}$

A number of phase III studies have assessed VEGF pathway inhibitors as first-line therapy for advanced NSCLC. At present, only one has demonstrated an OS benefit. ${ }^{1}$ Sorafenib plus chemotherapy did not achieve OS improvements in either the ESCAPE ${ }^{22}$ (sorafenib plus carboplatin/paclitaxel in squamous or nonsquamous NSCLC) or NEXUS ${ }^{23}$ (NSCLC Research Experience Utilizing Sorafenib; sorafenib plus cisplatin/gemcitabine in nonsquamous NSCLC) studies, although PFS was improved in NEXUS. Lastly, in BR24, a phase II/III study of carboplatin/paclitaxel with or without cediranib in squamous or nonsquamous NSCLC, PFS and ORR were improved over placebo plus carboplatin/paclitaxel; however, the study was halted because cediranib at $30 \mathrm{mg} / \mathrm{d}$ was associated with increased incidences of severe hypertension, gastrointestinal toxicity, and

\begin{tabular}{|c|c|c|c|c|c|c|c|c|}
\hline \multirow[b]{3}{*}{ Response } & \multicolumn{4}{|c|}{ Nonsquamous Analysis Set } & \multicolumn{4}{|c|}{ Adenocarcinoma Subanalysis Set } \\
\hline & \multicolumn{2}{|c|}{$\begin{array}{c}\text { Arm A, } \\
\text { Motesanib }+C / P \\
(n=541) \\
\end{array}$} & \multicolumn{2}{|c|}{$\begin{array}{c}\text { Arm B, } \\
\text { Placebo }+\mathrm{C} / \mathrm{P} \\
(\mathrm{n}=549)\end{array}$} & \multicolumn{2}{|c|}{$\begin{array}{c}\text { Arm A, } \\
\text { Motesanib }+C / P \\
(n=448) \\
\end{array}$} & \multicolumn{2}{|c|}{$\begin{array}{c}\text { Arm B, } \\
\text { Placebo }+C / P \\
(n=442)\end{array}$} \\
\hline & No. & $\%$ & No. & $\%$ & No. & $\%$ & No. & $\%$ \\
\hline Patients with measurable disease at baseline & 523 & 97 & 527 & 96 & 433 & 97 & 422 & 95 \\
\hline \multicolumn{9}{|l|}{ Response assessment } \\
\hline Confirmed CR & 5 & $<1$ & 2 & $<1$ & 5 & 1 & 1 & $<1$ \\
\hline Confirmed PR & 204 & 39 & 133 & 25 & 166 & 38 & 105 & 25 \\
\hline SD† & 207 & 40 & 265 & 50 & 182 & 42 & 214 & 51 \\
\hline PD & 35 & 7 & 80 & 15 & 26 & 6 & 64 & 15 \\
\hline Unevaluableł & 5 & $<1$ & 2 & $<1$ & 5 & 1 & 2 & $<1$ \\
\hline Not done§ & 67 & 13 & 45 & 9 & 49 & 11 & 36 & 9 \\
\hline Confirmed objective response (CR or PR) & 209 & 40 & 135 & 26 & 171 & 39 & 106 & 25 \\
\hline Difference, \% & \multicolumn{4}{|c|}{14.3} & \multicolumn{4}{|c|}{14.4} \\
\hline $95 \% \mathrm{Cl}$ & \multirow{2}{*}{\multicolumn{4}{|c|}{$\begin{array}{l}8.7 \text { to } 20.0 \\
<.001\end{array}$}} & \multicolumn{4}{|c|}{8.2 to 20.6} \\
\hline$P \|$ & & & & & & & & \\
\hline Responders with measurable disease at baseline & 209 & 39 & 135 & 25 & 171 & 38 & 106 & 24 \\
\hline Duration of response, months & \multicolumn{2}{|c|}{5.8} & \multicolumn{2}{|c|}{5.0} & \multicolumn{2}{|c|}{5.9} & \multicolumn{2}{|c|}{5.5} \\
\hline $95 \% \mathrm{Cl}$ & \multicolumn{2}{|c|}{5.3 to 6.5} & \multicolumn{2}{|c|}{4.4 to 5.6} & \multicolumn{2}{|c|}{5.5 to 6.9} & \multicolumn{2}{|c|}{4.4 to 5.7} \\
\hline \multicolumn{9}{|c|}{$\begin{array}{l}\text { Abbreviations: C/P, carboplatin/paclitaxel; CR, complete response; PD, progressive disease; PR, partial response; RECIST, Response Evaluation Criteria in Solic } \\
\text { Tumors; SD, stable disease. } \\
\text { "Assessed by investigators per RECIST version 1.0. The nonsquamous analysis set included all patients randomly assigned who had nonsquamous histology. The } \\
\text { adenocarcinoma analysis set included all patients randomly assigned who had adenocarcinoma histology. The denominator for all response categories was the } \\
\text { number of patients with measurable disease at baseline. } \\
\text { tPatients with an assessment of PR or CR not confirmed at least } 4 \text { weeks later were classified as having SD. } \\
\text { łPatients with an assessment of CR, PR, or SD before the first scheduled assessment of response without an additional assessment of response. } \\
\text { \$Patients for whom imaging was not performed at the scheduled assessment of response. } \\
\text { \|From Cochran-Mantel-Haenszel test stratified by the randomization stratification factors. }\end{array}$} \\
\hline
\end{tabular}




\begin{tabular}{|c|c|c|c|c|}
\hline \multicolumn{5}{|c|}{ Table 3. Adverse Events } \\
\hline \multirow[b]{2}{*}{$\mathrm{AE}$} & \multicolumn{2}{|c|}{$\begin{array}{c}\text { Arm A, } \\
\text { Motesanib } \\
+\mathrm{C} / \mathrm{P} \\
(\mathrm{n}=533) \\
\end{array}$} & \multicolumn{2}{|c|}{$\begin{array}{c}\text { Arm B, } \\
\text { Placebo } \\
+ \text { C/P } \\
(n=539)\end{array}$} \\
\hline & No. & $\%$ & No. & $\%$ \\
\hline Patients with any $\mathrm{AE}$ & 512 & 96 & 520 & 96 \\
\hline Grade 3 & 201 & 38 & 192 & 36 \\
\hline Grade 4 & 113 & 21 & 77 & 14 \\
\hline Grade 5 & 74 & 14 & 50 & 9 \\
\hline \multicolumn{5}{|l|}{$\begin{array}{c}\text { AEs with a } \geq 5 \% \text { difference in } \\
\text { incidence between arms }\end{array}$} \\
\hline Diarrhea & 255 & 48 & 118 & 22 \\
\hline Nausea & 222 & 42 & 176 & 33 \\
\hline Decreased appetite & 186 & 35 & 147 & 27 \\
\hline Vomiting & 178 & 33 & 142 & 26 \\
\hline Fatigue & 177 & 33 & 151 & 28 \\
\hline Neutropenia & 149 & 28 & 110 & 20 \\
\hline Hypertension & 139 & 26 & 35 & 6 \\
\hline Thrombocytopenia & 112 & 21 & 83 & 15 \\
\hline Rash & 97 & 18 & 57 & 11 \\
\hline Weight decreased & 93 & 17 & 46 & 9 \\
\hline Abdominal pain & 90 & 17 & 30 & 6 \\
\hline Headache & 82 & 15 & 49 & 9 \\
\hline Stomatitis & 59 & 11 & 26 & 5 \\
\hline Proteinuria & 47 & 9 & 16 & 3 \\
\hline Gallbladder-related disorder* & 44 & 8 & 2 & $<1$ \\
\hline Patients with serious AEs & 261 & 49 & 184 & 34 \\
\hline \multicolumn{5}{|l|}{ Serious grade $\geq 3$ AEst } \\
\hline Neutropenia & 28 & 5 & 12 & 2 \\
\hline Diarrhea & 25 & 5 & 4 & $<1$ \\
\hline Febrile neutropenia & 23 & 4 & 15 & 3 \\
\hline Pneumonia & 20 & 4 & 7 & 1 \\
\hline Dehydration & 19 & 4 & 4 & $<1$ \\
\hline Non-small-cell lung cancer & 16 & 3 & 12 & 2 \\
\hline Thrombocytopenia & 14 & 3 & 6 & 1 \\
\hline Pulmonary embolism & 12 & 2 & 17 & 3 \\
\hline Anemia & 12 & 2 & 11 & 2 \\
\hline Dyspnea & 11 & 2 & 20 & 4 \\
\hline Vomiting & 11 & 2 & 7 & 1 \\
\hline General physical health deterioration & 11 & 2 & 4 & $<1$ \\
\hline Cholecystitis & 11 & 2 & 0 & 0 \\
\hline \multicolumn{5}{|c|}{$\begin{array}{l}\text { NOTE. AEs are reported for all patients with nonsquamous histology who } \\
\text { received } \geq 1 \text { dose of motesanib or placebo and include events occurring } \\
\text { during treatment and within } 30 \text { days of the last administration of study } \\
\text { treatment. } \\
\text { Abbreviations: AE, adverse event; C/P, carboplatin/paclitaxel. } \\
\text { *Includes cholecystitis, acute and chronic cholecystitis, cholelithiasis; gall- } \\
\text { bladder enlargement, edema, and perforation; hydrocholecystis (the differ- } \\
\text { ence in incidence between arms for individual AEs was }<5 \% \text { ). } \\
\quad \text { In } \geq 2 \% \text { of patients in either treatment arm. } \\
\neq \text { Patients with non-small-cell lung cancer reported as an AE by investigators. }\end{array}$} \\
\hline
\end{tabular}

febrile neutropenia and was not considered tolerable. ${ }^{24}$ Furthermore, two randomized studies evaluating VEGF pathway inhibitors as second-line therapy in advanced NSCLC failed to meet their primary end points. ${ }^{25,26}$ The results from MONET1 add to the growing body of evidence suggesting that VEGF pathway inhibitors in combination with chemotherapy do not provide a significant clinical benefit to unselected patients with (nonsquamous) NSCLC. Additional studies do not seem to be warranted unless better patient selection using biomarkers, for example, can be achieved. Despite ongoing efforts, ${ }^{27}$ such biomarkers have remained elusive. MONET1 is the first large phase III study to prospectively test a biomarker hypothesis for an antiangiogenic therapy in NSCLC. Data from the preceding phase II study of carboplatin/paclitaxel plus motesanib or bevacizumab suggested that increased PLGF might be a marker of therapeutic response to motesanib treatment. ${ }^{12}$ This hypothesis was supported by similar findings of associations between fold-change in PLGF and outcomes in patients with advanced thyroid cancer $^{17}$ and human epidermal growth factor receptor $2-$ negative metastatic breast cancer ${ }^{12}$ receiving motesanib. However, the data could not be confirmed in MONET1; there was no association between changes in PLGF and OS in the motesanib arm.

Previous studies suggested that NSCLC tumor histology influences response to certain chemotherapy regimens ${ }^{28}$ and targeted agents (including VEGF pathway inhibitors). ${ }^{6,29}$ A retrospective analysis of the E4599 study reported a 4-month improvement in OS with the addition of bevacizumab to carboplatin/paclitaxel among patients with adenocarcinoma histology. ${ }^{6}$ On the basis of those data, we conducted a prospectively defined analysis of efficacy in the subset of patients with adenocarcinoma histology. Although a statistically significant improvement in OS was not achieved, it is noteworthy that in prespecified subgroup analyses, the HR for patients with adenocarcinoma histology was 0.880 versus 1.012 for those with other nonsquamous histologies.

Prespecified subgroup analyses also indicated differences in OS by ethnicity and geographic location. The subanalyses data suggest that a highly selected patient population might have a greater likelihood to benefit. Specifically, results from the ethnicity/regional subanalysis indicate that Asian patients (one fourth of the enrolled patient population) may achieve better clinical outcome than nonAsian patients (data not shown), which may warrant a separate study in the future.

In summary, treatment with motesanib plus carboplatin/paclitaxel in this phase III study did not significantly improve OS and was associated with a higher incidence of AEs compared with placebo plus carboplatin/paclitaxel in patients with advanced nonsquamous NSCLC and in the subset of patients with adenocarcinoma histology.

\section{AUTHORS' DISCLOSURES OF POTENTIAL CONFLICTS OF INTEREST}

Although all authors completed the disclosure declaration, the following author(s) and/or an author's immediate family member(s) indicated a financial or other interest that is relevant to the subject matter under consideration in this article. Certain relationships marked with a " $U$ " are those for which no compensation was received; those relationships marked with a "C" were compensated. For a detailed description of the disclosure categories, or for more information about ASCO's conflict of interest policy, please refer to the Author Disclosure Declaration and the Disclosures of Potential Conflicts of Interest section in Information for Contributors. Employment or Leadership Position: Sheryl McCoy, Amgen (C); Bin Yao, Amgen (C); Yong-jiang Hei, Amgen (C); Francesco Galimi, Amgen (C) Consultant or Advisory Role: Giorgio V. Scagliotti, Eli Lilly (C); Keunchil Park, Amgen (C); Fiona Blackhall, Amgen (U); Robert Pirker, Amgen (C); Tudor-Eliade Ciuleanu, Amgen (C); Mircea Dediu, F. Hoffmann-La Roche (C); David R. Spigel, Amgen (U) Stock Ownership: Sheryl McCoy, Amgen; Bin Yao, Amgen; Yong-jiang Hei, Amgen; Francesco Galimi, Amgen Honoraria: Giorgio V. Scagliotti, AstraZeneca, Eli Lilly, Pfizer, Roche; Tudor-Eliade Ciuleanu, Amgen; Mircea Dediu, F. Hoffmann-La Roche Research Funding: Yukito Ichinose, 
Amgen/Takeda Bio; Fiona Blackhall, Amgen Expert Testimony: None Other Remuneration: None

\section{AUTHOR CONTRIBUTIONS}

Conception and design: Giorgio V. Scagliotti, Keunchil Park, Yong-jiang Hei Provision of study materials or patients: Giorgio V. Scagliotti, Keunchil Park, Kaoru Kubota, Tudor-Eliade Ciuleanu, Natividad Martinez Banaclocha, David R. Spigel
Collection and assembly of data: Giorgio V. Scagliotti, Ihor Vynnychenko, Yukito Ichinose, Tudor-Eliade Ciuleanu, Oleksandr Sydorenko, Mircea Dediu, Natividad Martinez Banaclocha, Sheryl McCoy, Bin Yao

Data analysis and interpretation: Giorgio V. Scagliotti, Ihor Vynnychenko, Keunchil Park, Kaoru Kubota, Fiona Blackhall, Robert Pirker, Rinat Galiulin, Tudor-Eliade Ciuleanu, Zsolt Papai-Szekely, Sheryl McCoy, Bin Yao, Yong-jiang Hei, Francesco Galimi, David R. Spigel

Manuscript writing: All authors Final approval of manuscript: All authors

\section{REFERENCES}

1. Sandler A, Gray R, Perry MC, et al: Paclitaxelcarboplatin alone or with bevacizumab for non-smallcell lung cancer. N Engl J Med 355:2542-2550, 2006

2. Reck M, von Pawel J, Zatloukal P, et al: Phase III trial of cisplatin plus gemcitabine with either placebo or bevacizumab as first-line therapy for nonsquamous non-small-cell lung cancer: AVAil. J Clin Oncol 27:1227-1234, 2009

3. Reck $M$, von Pawel J, Zatloukal $P$, et al: Overall survival with cisplatin-gemcitabine and bevacizumab or placebo as first-line therapy for nonsquamous non-small-cell lung cancer: Results from a randomised phase III trial (AVAiL). Ann Oncol 21: 1804-1809, 2010

4. Scagliotti G, Govindan R: Targeting angiogenesis with multitargeted tyrosine kinase inhibitors in the treatment of non-small cell lung cancer. Oncologist 15:436-446, 2010

5. Jain RK, Duda DG, Willett CG, et al: Biomarkers of response and resistance to antiangiogenic therapy. Nat Rev Clin Oncol 6:327-338, 2009

6. Sandler A, Yi J, Dahlberg S, et al: Treatment outcomes by tumor histology in Eastern Cooperative Group Study E4599 of bevacizumab with paclitaxel/carboplatin for advanced non-small cell lung cancer. J Thorac Oncol 5:1416-1423, 2010

7. Polverino A, Coxon A, Starnes $C$, et al: AMG 706, an oral, multikinase inhibitor that selectively targets vascular endothelial growth factor, plateletderived growth factor, and kit receptors, potently inhibits angiogenesis and induces regression in tumor xenografts. Cancer Res 66:8715-8721, 2006

8. Sherman SI, Wirth LJ, Droz JP, et al: Motesanib diphosphate in progressive differentiated thyroid cancer. N Engl J Med 359:31-42, 2008

9. Rosen LS, Kurzrock R, Mulay M, et al: Safety, pharmacokinetics, and efficacy of AMG 706, an oral multikinase inhibitor, in patients with advanced solid tumors. J Clin Oncol 25:2369-2376, 2007

10. Schlumberger MJ, Elisei $R$, Bastholt $L$, et al: Phase II study of safety and efficacy of motesanib in patients with progressive or symptomatic, advanced or metastatic medullary thyroid cancer. J Clin Oncol 27:3794-3801, 2009

11. Blumenschein GR Jr, Kabbinavar F, Menon $H$, et al: A phase II, multicenter, open-label randomized study of motesanib or bevacizumab in combination with paclitaxel and carboplatin for advanced nonsquamous non-small-cell lung cancer. Ann Oncol 22:2057-2067, 2011

12. Bass MB, Davis MT, Kivman $L$, et al: Placental growth factor as a marker of therapeutic response to treatment with motesanib in patients with progressive advanced thyroid cancer, advanced nonsquamous non-small-cell lung cancer, and locally recurrent or advanced metastatic breast cancer. J Clin Oncol 28:15s, 2010 (suppl; abstr 3037)

13. Autiero $M$, Waltenberger $J$, Communi $D$, et al: Role of PIGF in the intra- and intermolecular cross talk between the VEGF receptors Flt1 and Flk1. Nat Med 9:936-943, 2003

14. Therasse $P$, Arbuck SG, Eisenhauer EA, et al: New guidelines to evaluate the response to treatment in solid tumors. European Organization for Research and Treatment of Cancer, National Cancer Institute of the United States, National Cancer Institute of Canada. J Natl Cancer Inst 92:205-216, 2000

15. Cox DR, Oakes D: Analysis of Survival Data. Boca Raton, FL, Chapman \& Hall/CRC, 1984

16. Patterson SD, Davis MT, Mackey J, et al: Biomarkers as potential predictors of response to treatment with motesanib or bevacizumab in combination with paclitaxel $(P)$ in patients (Pts) with locally recurrent or advanced metastatic breast cancer. J Clin Oncol 28:15s, 2010 (suppl; abstr 1048)

17. Bass MB, Sherman SI, Schlumberger MJ, et al: Biomarkers as predictors of response to treatment with motesanib in patients with progressive advanced thyroid cancer. J Clin Endocrinol Metab 95:5018-5027, 2010

18. Blumenschein GR Jr, Reckamp K, Stephenson GJ, et al: Phase 1b study of motesanib, an oral angiogenesis inhibitor, in combination with carboplatin/paclitaxel and/or panitumumab for the treatment of advanced non-small-cell lung cancer. Clin Cancer Res 16:279-290, 2010

19. Kotasek D, Tebbutt N, Desai J, et al: Safety and pharmacokinetics of motesanib in combination with gemcitabine and erlotinib for the treatment of solid tumors: A phase 1b study. BMC Cancer 11: 313, 2011

20. Tebbutt NC, Lipton LR, Price TJ, et al: The effect of motesanib treatment on the gallbladder: A randomized phase $\mathrm{lb}$ study in patients (pts) with advanced solid tumors. J Clin Oncol 29, 2011 (suppl; abstr e13555)

21. Johnson DH, Fehrenbacher L, Novotny WF, et al: Randomized phase II trial comparing bevacizumab plus carboplatin and paclitaxel with carboplatin and paclitaxel alone in previously untreated locally advanced or metastatic non-small-cell lung cancer. J Clin Oncol 22:2184-2191, 2004

22. Scagliotti G, Novello S, von Pawel J, et al: Phase III study of carboplatin and paclitaxel alone or with sorafenib in advanced non-small-cell lung cancer. J Clin Oncol 28:1835-1842, 2010

23. Gatzemeier $U$, Eisen $T$, Santoro $A$, et al: Sorafenib (S) + gemcitabine/cisplatin (GC) vs GC alone in the first-line treatment of advanced nonsmall cell lung cancer (NSCLC): phase III NSCLC research EXperience Utilizing Sorafenib (NEXUS) trial. Ann Oncol 21:viii7, 2010 (suppl; abstr LBA16)

24. Goss GD, Arnold A, Shepherd FA, et al: Randomized, double-blind trial of carboplatin and paclitaxel with either daily oral cediranib or placebo in advanced non-small-cell lung cancer: NCIC clinical trials group BR24 study. J Clin Oncol 28:49-55, 2010

25. de Boer RH, Arrieta Ó, Yang $\mathrm{CH}$, et al: Vandetanib plus pemetrexed for the second-line treatment of advanced non-small-cell lung cancer: A randomized, double-blind phase III trial. J Clin Oncol 29: 1067-1074, 2011

26. Herbst RS, Sun $Y$, Eberhardt WE, et al: Vandetanib plus docetaxel versus docetaxel as second-line treatment for patients with advanced non-small-cell lung cancer (ZODIAC): A doubleblind, randomised, phase 3 trial. Lancet Oncol 11:619-626, 2010

27. Herbst RS, Blumenschein GRJ, Kim ES, et al: Sorafenib treatment efficacy and KRAS biomarker status in the Biomarker-Integrated Approaches of Targeted Therapy for Lung Cancer Elimination (BATTLE) trial. J Clin Oncol 28:565s, 2010 (suppl; abstr 7609)

28. Scagliotti GV, De Marinis $F$, Rinaldi $M$, et al: The role of histology with common first-line regimens for advanced non-small cell lung cancer: A brief report of the retrospective analysis of a threearm randomized trial. J Thorac Oncol 4:1568-1571, 2009

29. Mok TS, Wu YL, Thongprasert $S$, et al: Gefitinib or carboplatin-paclitaxel in pulmonary adenocarcinoma. N Engl J Med 361:947-957, 2009 